\title{
Ignition characteristics of a bio-derived class of saturated and unsaturated furans for engine applications
}

\author{
Alena Sudholt ${ }^{\mathrm{a}, \mathrm{b}, *}$, Liming Cai ${ }^{\mathrm{a}}$, Joshua Heyne ${ }^{\mathrm{b}}$, Francis M. Haas ${ }^{\mathrm{b}}$, Heinz \\ Pitsch $^{\mathrm{a}}$, Frederick L. Dryer ${ }^{\mathrm{b}}$ \\ ${ }^{a}$ Institute for Combustion Technology, Templergraben 64, RWTH Aachen University, \\ 52056 Aachen, Germany \\ ${ }^{b}$ Department of Mechanical and Aerospace Engineering, Princeton University, Princeton, \\ NJ 08544, USA
}

\begin{abstract}
Ignition characteristics in the form of derived cetane numbers (DCN) of (hydro)furanic species are investigated experimentally in an Ignition Quality Tester. Further, quantum chemistry calculations at CBS-QB3 level of theory are applied to determine bond dissociation energies (BDEs) and thereby suggest the initial reactions of the ignition process for all of these fuels. Using the calculated BDEs, it is found that the ignition characteristics are similar among furans and among tetrahydrofurans, but strongly differ between these molecular classes. It is shown that the ignition behavior of aromatic furans is determined by the ring structure, which correlates with a negligible side chain influence. Hence, furan fuel structures can be chosen with respect to feasibility of the production pathways and engine compatibility. On the contrary, the side chain length for tetrahydrofurans defines the potential application paradigm. Tetrahydrofurans with short side chains are candidates for SI application, whereas 2-butyltetrahydrofuran may be a candidate for diesel application. The influence of the number and location of double bonds in the ring is illustrated with the additional study of dihydrofurans, and the influence of other functional groups is evaluated for (tetrahydro)furfuryl alcohols.
\end{abstract}

To investigate possible fuel application scenarios, a second part of this study investigates DCNs of furanic fuel blends in n-heptane and diesel fuel.

\footnotetext{
*Corresponding author:

Email address: a.sudholt@itv.rwth-aachen.de (Alena Sudholt)
} 
A DCN mixing rule is found to be approximately linear and for blends with up to $20 \mathrm{~mol} \%$ furans, the side chain structure (alkyl, alcohol) has no distinct influence on the blend DCN.

Keywords: Derived cetane number, bond dissociation energies, furans, tetrahydrofurans

\section{Introduction}

The search for an efficient, sustainable transportation fuel from lignocellulosic biomass is a major aspect in the reduction of anthropogenic carbon dioxide emissions. In an effort to vertically integrate this search, RWTH Aachen University has compiled researchers from diverse fields (e.g. diesel engine researchers, combustion scientists, organic chemists, and chemical process engineers) in the "Tailor-Made Fuels from Biomass" (TMFB) project to develop possible fuel candidates evaluated by their physical properties, chemical kinetics, and engine performance. Further, new engine strategies are developed to yield high efficiency combined with low emissions [1]. A major challenge in this holistic approach is the simultaneous development of new production pathways for bio-fuels and the understanding of their combustion properties. Thus, analysis of production pathways and combustion properties will be used to determine which fuels meet the criteria for up scaling. Unfortunately, not all potential bio-fuel candidates can be tested equivalently, and a more fundamental understanding relating combustion properties to molecular structure is needed. The systematic understanding of the influence of fuel structures on the combustion performance of a fuel, as well as fast and meaningful experiments are hence crucial for the progress of the project. Furans and tetrahydrofurans (THFs) have been selected as potential candidates as part of the TMFB program. These candidates can be produced from lignocellulosic biomass through selective catalytic transformation steps with a variety of different side chains $[2,3]$. These production pathways have been illustrated by Voll and Marquardt using a reaction network analysis [2]. They investigated the complete process chain from the biomass separation into its components cellulose, hemicellulose, and lignin, over the production of platform molecules, such as furfural, hydroxymethylfurfural, itaconic acid, and levulinic acid (cf. supplementary material, Fig. S1), to the synthesis of potential transportation fuels. It is shown that the ring structure of the product fuel depends on the intermediate species, where the acid intermediates 
yield THFs and the furfural intermediates lead to the formation of furans. The side chain length and location of the product fuel can be influenced to some extent by the selection of different synthesis pathways.

In this study, the auto-ignition behavior and BDEs of furans and THFs are evaluated. The influence of the functional groups on engine performance is analyzed in terms of the derived cetane number (DCN), a parameter characterizing the ignitability of a fuel in a compression ignition engine.

For the smaller furans and THFs, several kinetic modeling and experimental investigations have been performed in recent years [4-10]. However, for furans and THFs with longer side chains (ethyl and larger) neither kinetic models nor experimental data are available. Only for 2-ethylfuran (2-EF), Zhang et al. [11] performed ab-initio calculations for H-abstraction from the fuel molecule by the hydroxyl radical.

The discovery of these production pathways presents major opportunities, and an investigation into the combustion properties of the bio-derived fuels is merited. In addition, data for a direct comparison of all of the discussed furanic species is required. In this study, ignition experiments were therefore performed at engine relevant conditions in an Ignition Quality Tester (IQT) for a wide range of furans, THFs, and structurally related dihydrofurans (Fig. 1). Some of these are commercially unavailable or they are produced only in small quantities including 2-EF, 2-butylfuran (2-BF), 2ethyltetrahydrofuran (2-ETHF) and 2-BTHF. These species were synthesized specifically for this experiment via novel lignocellulosic conversion routes within TMFB [3].

A standard reference value to describe fuel ignition behavior in compression ignition engines is the cetane number $(\mathrm{CN})$, which is obtained in cetane engine experiments. Typical compression ignition engines operate on fuels with a $\mathrm{CN}$ of 40 to 55 . In this study, the related derived cetane number was obtained for all fuels shown in Fig. 1. The main advantages of the DCN over the $\mathrm{CN}$ are of experimental nature. The IQT requires less fuel and time to obtain DCNs (with a higher repeatability) than conventional CN from cetane engine experiments. Nonetheless, the DCN values are directly comparable to the historically established $\mathrm{CN}[12]$.

In this study, the side chain influence on the ignition behavior of furan and THF is evaluated to identify the contribution of the functional groups under engine relevant conditions. As bio-fuels are often used in blends with fossil fuels, the furans and THFs are additionally investigated in blends with n-heptane and diesel. In Section 2, bond dissociation ener- 
gies (BDEs) for 2-EF, 2-BF, 2-furfuryl alcohol (2-FFOH), 2-ETHF, 2-BTHF, 2-tetrahydrofurfuryl alcohol (2-THFFOH), 2,3-dihydrofuran (2,3-DHF) and 2,5-dihydrofuran (2,5-DHF) are calculated with the CBS-QB3 [13] level of theory. These results are used to evaluate the fuel structure influence on the initial reactions and the overall ignition behavior for the furan and the THF groups. Section 3 describes the experimental setup and measurement approach. Furthermore, the DCN results of the pure fuels and the fuel/nheptane blends are presented in Sec. 4 and discussed in detail using the findings of Sec. 2.

\section{Kinetics}

Available kinetic models for small furans and THFs in combination with structural properties such as BDEs are used to analyze the initial fuel reactions during ignition. Simmie and Curran [4] calculated BDEs for small furans at CBS-QB3, CBS-APNO and G3 level of theory and used the results from the different calculation methods for an uncertainty prediction. Hence, their BDEs are mean values with standard deviations. The same approach was applied by Simmie [6] for small THFs. Along with the BDEs calculated in this study, these values are used to evaluate differences and common behaviors within the furan and the THF group. In addition, the BDEs and the initial reaction pathways provide the basis for interpreting the DCN data presented in Sec. 4.

\subsection{Bond dissociation energies}

The BDEs for the $\mathrm{C}-\mathrm{H}$ bonds for all molecules are shown in Tab. 1. They are presented for the radical resulting from an initiating $\mathrm{H}-$ or $\mathrm{CH}_{3}$ abstraction.

BDE calculations. Quantum chemistry calculations were conducted to determine the most stable molecule conformation for each of the regarded species and to obtain the carbon-hydrogen and carbon-carbon BDEs. All geometry optimization and frequency calculations were performed using the CBS-QB3 level of theory within the Gaussian09 suite of programs [14] and the BDEs for 2-methyltetrahydrofuran (2-MTHF) presented in this study are in good agreement with the BDEs given by Simmie [6]. The calculated BDEs from the CBS-QB3 approach allow for a global understanding of the influence of the molecular structures on the fuel ignition. 
A conformational analysis of 2-MTHF, 2-ETHF, 2-BTHF, 2-EF, and 2$\mathrm{BF}$ was conducted to determine the most stable conformer of each species. It was found that conformers with a $60^{\circ}$ (gauche) O1-C2-C6-C7 dihedral angle (cf. Fig. 1 for atom labeling) are more stable than the ones with a $180^{\circ}$ (trans) dihedral angle ${ }^{1}$.

Furans. Simmie and Curran [4] showed that the BDEs for furan ring carbon hydrogen bonds are the strongest $\mathrm{C}-\mathrm{H}$ bonds known with BDEs of approximately $504 \mathrm{~kJ} \mathrm{~mol}^{-1}$. This value is higher than the one in the corresponding aromatic species (C-H BDE for benzene $472 \mathrm{~kJ} \mathrm{~mol}^{-1}$ ). The BDEs of the $\mathrm{C}-\mathrm{H}$ bond in the methyl side chains of 2-MF, 3-methylfuran (3-MF) and 2,5-dimethylfuran $(2,5-\mathrm{DMF})$ are significantly smaller $\left(\approx 360 \mathrm{~kJ} \mathrm{~mol}^{-1}[4]\right)$. These observations also hold for the newly investigated 2-EF and 2-BF. Their ring carbon $\mathrm{C}-\mathrm{H}$ BDEs agree well with those of the smaller species, and the C6-H BDEs in the side chains are even lower $\left(\approx 350 \mathrm{~kJ} \mathrm{~mol}^{-1}\right)$ as those of the methylated furans. However, all other $\mathrm{C}-\mathrm{H}$ bonds in the side chain are in the range of close to $420 \mathrm{~kJ} \mathrm{~mol}^{-1}$ for the secondary carbon atoms and $430 \mathrm{~kJ} \mathrm{~mol}^{-1}$ for the primary carbon atom and hence considerably stronger than the $\mathrm{C} 6-\mathrm{H}$ bonds. These values are consistent with the ones found for primary and secondary carbons in linear alkanes [15] and in agreement with the general order of C-H bond strengths for hydrocarbons: Primary > secondary $>$ tertiary. Considering these BDE distributions, H-abstraction mainly occurs at the $\mathrm{C} 6$ atom on the side chain for alkylated furans.

Tetrahydrofurans. As all bonds in the THF molecules are saturated, the variation between the $\mathrm{C}-\mathrm{H}$ bond strengths is much less distinct than for furans. For THFs, the ring carbon C-H BDEs are lower at the carbon atoms adjacent to the oxygen atom. For THF, this results in a BDE of $392.4 \mathrm{~kJ} \mathrm{~mol}^{-1}$ for the $\mathrm{C} 2-\mathrm{H}$ bond and $411.6 \mathrm{~kJ} \mathrm{~mol}^{-1}$ for the $\mathrm{C} 3-\mathrm{H}$ bond [6]. For the alkylated THFs, the $\mathrm{C}-\mathrm{H}$ bond at the $\mathrm{C} 2$ carbon atom is approximately $3 \mathrm{~kJ} \mathrm{~mol}^{-1}$ lower than the $\mathrm{C}-\mathrm{H}$ bonds of the unsubstituted $\mathrm{C} 5$ carbon atom, as the produced radical site is located at a secondary carbon atom and additionally stabilized by the lone pairs of electrons of the adjacent oxygen atom. Similar to the furans, the BDEs of the $\mathrm{C}-\mathrm{H}$ bonds in the side chain of the tetrahydrofuranic species are in the range of paraffinic primary and secondary C-H

\footnotetext{
${ }^{1}$ The O1-C2-C6-C7 dihedral angle describes the orientation of the planes spanned by the $\mathrm{O} 1-\mathrm{C} 2-\mathrm{C} 6$ atoms and the $\mathrm{C} 2-\mathrm{C} 6-\mathrm{C} 7$ atoms.
} 
bonds [15], whereas the secondary ring carbon atoms have slightly lower $\mathrm{C}-\mathrm{H}$ BDEs. As the side chain $\mathrm{C}-\mathrm{H}$ bonds and the $\mathrm{C}-\mathrm{H}$ bonds of the nonoxygenated ring carbon atoms are approximately 20 to $30 \mathrm{~kJ} \mathrm{~mol}^{-1}$ higher than the $\mathrm{C} 2-\mathrm{H}$ BDE, H-abstraction at the $\mathrm{C} 2$ atom prevails for the tetrahydrofuranic species.

Dihydrofurans. Even though dihydrofurans have not been synthesized through the novel production pathways from lignocellulosic biomass discussed above, they are considered in this study for two reasons: First, they are formed as intermediate products in the combustion of THFs $[6,16]$. Second, the studies on 2,3-DHF and 2,5-DHF provide additional insight into the influence of the number and location of double bonds.

The C-H bonds at the unsaturated ring carbons of the 2,3-DHF are similar to the furan ring $\mathrm{C}-\mathrm{H}$ bonds, but the $\mathrm{C} 5-\mathrm{H}$ BDE was found to be $\approx 10 \mathrm{~kJ} \mathrm{~mol}^{-1}$ weaker than the $\mathrm{C} 4-\mathrm{H}$ bond. This is in good agreement with the values for 2,3-DHF obtained by Simmie [6]. As expected, the BDEs of the $\mathrm{H}$-abstraction from the saturated carbons are significantly lower than those for the unsaturated carbon atoms with $394.0 \mathrm{~kJ} \mathrm{~mol}^{-1}$ for the abstraction at the $\mathrm{C} 2$ position and $343.8 \mathrm{~kJ} \mathrm{~mol}^{-1}$ at the $\mathrm{C} 3$ position. The difference between the BDEs of the $\mathrm{C} 2-\mathrm{H}$ and the $\mathrm{C} 3-\mathrm{H}$ bond are due to the fact that the produced 2,3-DHF-3R radical is resonantly stabilized by the adjacent double bond in the ring, whereas the $2,3-\mathrm{DHF}-2 \mathrm{R}$ radical is stabilized to a lesser degree by the lone pairs of electrons of the oxygen atom. Thus, H-abstraction mainly occurs at the $\mathrm{C} 3$ ring carbon atom.

The BDEs for 2,5-DHF are slightly lower than those for 2,3-DHF at comparable positions with a BDE of $485.4 \mathrm{~kJ} \mathrm{~mol}^{-1}$ for the $\mathrm{C}-\mathrm{H}$ bond at the unsaturated $\mathrm{C} 3$ carbon atom and $329.9 \mathrm{~kJ} \mathrm{~mol}^{-1}$ at the saturated $\mathrm{C} 2$ carbon atom. Due to the central position of the double bond in the ring and the influence of the oxygen atom, 2,5-DHF-2R is highly stabilized. Hence, the most likely $\mathrm{H}$-abstraction of the 2,5-DHF molecule occurs at the $\mathrm{C} 2$ position. Note, however that even though the resonance stabilization of the produced radicals leads to an easy $\mathrm{H}$-abstraction, the produced radicals are relatively stable, unreactive species.

Alcohols. The ring carbon BDEs of 2-FFOH are consistent with those of the alkylated furans, only the $\mathrm{C} 3-\mathrm{H} \mathrm{BDE}$ of $2-\mathrm{FFOH}$ is slightly larger with $508.3 \mathrm{~kJ} \mathrm{~mol}^{-1}$. Also, the BDE for H-abstraction from the hydroxyl group is similar to those in linear alcohols [17]. The side chain $\mathrm{C} 6-\mathrm{H}$ bond, on the 
other hand, is influenced by the hydroxyl group. With $343.7 \mathrm{~kJ} \mathrm{~mol}^{-1}$, this bond is weaker than the $\mathrm{C} 6-\mathrm{H}$ bond in the corresponding alkylated furan $2-\mathrm{EF}$. However, the general distribution of the $\mathrm{C}-\mathrm{H}$ BDEs is very similar for 2-FFOH and 2-EF.

For the saturated 2-THFFOH, the BDEs at the 3-, 4-, and 5-position are similar those of the alkylated THFs and the $\mathrm{O}-\mathrm{H}$ bond resembles that of 2-FFOH and linear alcohols. The $\mathrm{C} 2-\mathrm{H}$ bond $\left(397.2 \mathrm{~kJ} \mathrm{~mol}^{-1}\right)$, however, is stronger than that of the THFs and similar to the $\mathrm{C} 5-\mathrm{H}$ bond $\left(396.2 \mathrm{~kJ} \mathrm{~mol}^{-1}\right)$. Since the $\mathrm{C} 6-\mathrm{H}$ bond is only $6 \mathrm{~kJ} \mathrm{~mol}^{-1}$ larger than the $\mathrm{C} 2$ $\mathrm{H}$ and $\mathrm{C} 5-\mathrm{H}$ bonds, an unambiguous conclusion on the initial $\mathrm{H}$-abstraction reactions cannot be drawn and further detailed kinetic studies need to be performed for a comprehensive determination of the initial reaction steps and their contribution to the depletion of the 2-THFFOH molecule.

\subsection{Initial reactions}

The previously discussed simulation results show that the ring structures and to some extent the hydroxyl group determine the $\mathrm{C}-\mathrm{H}$ BDE results. Hence, the BDEs are similar within the groups of either furans or THFs, and it is assumed that within these groups, the ignition proceeds through comparable pathways. Hence, reaction schemes established for the smaller species such as 2,5-DMF [18] will be applied to the related larger species. For the larger molecules, low temperature reaction pathways seem possible and are discussed in context of the DCN results in Sec. 4.

Furans. Using the modeling study of Somers et al. [18] for 2,5-DMF, the computational studies for various furans by Simmie et al. [4], the study on the reaction of 2-EF with the hydroxyl radical by Zhang et al. [11], and the new BDE results, the four general reaction pathways for the ignition of furans are determined, cf. Fig. 2. Under oxidative conditions, H-abstraction on the side chain and $\mathrm{H}_{-}, \mathrm{OH}-$, and $\mathrm{CH}_{3}$-addition to the ring dominate the reaction pathway [18]. Both of these pathways lead to the formation of resonantly stabilized radicals and are the reason for the observed lack of reactivity of the furanic species.

Tetrahydrofurans. Contrary to the combustion of the furans, the oxidation of the tetrahydrofuranic species is generally initiated by $\mathrm{H}$-abstraction at the $\mathrm{C} 2$ or $\mathrm{C} 5$ atom in the THF ring [6]. The following ring opening and $\beta$-scission yields alkenes and highly reactive aldehyde and ketone radicals, cf. Fig. 3. 


\section{Experiments}

Ignition Quality Tester. The global ignition behavior of furans, tetrahydrofurans and dihydrofurans was studied in an IQT. The IQT is a constant volume combustion chamber in which liquid fuel is injected into pressurized preheated air. It operates with small amounts of fuel under engine relevant conditions $(p=21.1 \mathrm{~atm}, 788 \mathrm{~K} \leq T \leq 848 \mathrm{~K})$, and yields an ignition delay time (ID). Through an invertible unambiguous correlation, the derived cetane number $(\mathrm{DCN})$ is defined by measured ID as

$$
\begin{aligned}
& \mathrm{DCN}=4.46+\frac{186.6}{\mathrm{ID}} \\
& \quad \text { for ID } \in[3.1 \mathrm{~ms}, 6.5 \mathrm{~ms}] \\
& \mathrm{DCN}=83.99(\mathrm{ID}-1.512)^{-0.658}+3.547 \\
& \quad \text { for ID }<3.1 \mathrm{~ms} ; \mathrm{ID}>6.5 \mathrm{~ms},
\end{aligned}
$$

for further details cf. [19-21]. In this study, the DCN values and not the ignition delays are used as basis for discussion, as the cetane number is the historically established benchmark criterion of fuels for diesel applications. The presentation of DCN values for novel bio-fuels enables comparisons to data from other studies and fuel species. Furthermore, such data are pertinent to estimating the DCN of blends of these species with other fuels. Nonetheless, both parameters are easily inter-convertible and the results presented in Fig. 7 are additionally shown in terms of ignition delay in the supplementary material. Similar to cetane engine experiments [22], the ignition in an IQT [21] is affected by three aspects: Fuel evaporation, fuel/air mixture formation and chemical reactions. As the individual influences of each aspect on $\mathrm{CN}$ or DCN determinations are difficult to quantitatively extract, the DCN represents a global fuel behavior in an engine-related environment and not a target for detailed kinetic modeling.

To qualitatively assess how the relative effects of physical and chemical kinetic properties on the DCNs of furan and 2-MF, DCN measurements were obtained for each of these species blended with a single component hydrocarbon, n-heptane, and a full distillation curve reference diesel fuel. In Figure 4, the normalized DCN data shows no deviation between the respective n-heptane and diesel blends. Hence, it is assumed that the DCNs are mainly influenced by the reaction chemistry of the fuels and discussed in such terms in Sec. 4. Note that all mixture DCN data is additionally presented in 
tables in the supplementary material.

The experimental procedure of this study is as follows: For each fuel sample, at least three IQT cycles were measured. One cycle consists of 15 pre-injections, which are not used for the data evaluation, and 32 injections. Hence, each reported DCN is a mean value of at least 96 single measurements with a standard deviation of $\pm 1.5 \mathrm{DCN}$ for most measurements. The DCN measurements of the pure furans with short side chains have a standard deviation of $\pm 4 \mathrm{DCN}$. For the fuels with high standard deviations, a minimum of 5 runs and 160 single measurements was performed. Due to its low boiling point, the DCN of furan could not be measured directly. Therefore, pure furan IDs were extrapolated from a furan/n-heptane mixture study and transformed to DCN with an error of $\pm 10 \%$. For the extrapolation, furan/nheptane measurements up to concentrations of $85 \mathrm{~mol} \%$ furan were used in addition to the assumption of analogous mixture ignition behavior among furan, 2-MF and 2,5-DMF.

\section{Results}

\subsection{DCN of pure fuels}

In Figure 5, the measured DCNs for all pure fuel species are presented and grouped as follows: (Alkylated) furans, (alkylated) tetrahydrofurans, dihydrofurans, furfuryl and tetrahydrofurfuryl alcohols and n-heptane (used both as reference fuel and as a component of the studied blends). Further, the minimum required cetane numbers for diesel fuels in the European Union and the United States are indicated. All fuels with a DCN higher than these values are potential diesel candidates. Fuels with very low DCNs are highly knock-resistant and hence interesting candidates for spark-ignition (SI) engine applications. Therefore, the DCN corresponding to a RON 90 fuel is indicated as reference value for a gasoline fuel [23]. All species with a DCN lower than that of the RON 90 fuel could be considered for application in SI engines. With respect to these limits, it is obvious that the low DCN of most of the tested fuels identifies them as potential candidates for SI engine application, whereas only 2-BTHF has a high enough DCN to be a candidate for direct diesel application. 2-ETHF fulfills neither criteria and cannot be used for engine applications as pure component. Its applicability in fuel blends, however, is possible and is discussed in Sec. 4.2.

Figure 6 depicts the influence of the side chain length and the double bonds on the DCN results. The increase of DCN for all furans and tetrahy- 
drofurans is approximately proportional to the side chain length, although it is much more distinct for the tetrahydrofuranic than for the furanic species. On the contrary, the increase of the number of double bonds in the ring and the resulting aromaticity lead to a decrease in the fuel reactivity. This result is consistent with the results of the presented BDE study, the general inhibitive character of double bonds in hydrocarbons [24] and the high chemical inhibition and knock-resistance of other unsaturated ring structures, such as toluene [25]. Hence, the furan ring dominates the global ignition behavior for the aromatic furans, which can be seen in the low variance among their DCNs, whereas the side chain strongly influences the DCN values for the tetrahydrofurans.

In Section 2, it was shown that the major reaction pathways for the furanic species are $\mathrm{H}$-abstraction, as well as $\mathrm{H}-$, $\mathrm{OH}$ - and $\mathrm{CH}_{3}$-addition reactions which lead to the formation of unreactive, resonantly stabilized radicals. That the length of the alkyl chain connected to the furan ring has only a minor influence on the DCN conforms to these findings, as the fuel reactivity is mainly determined by the degree of unsaturation of the intermediates species.

For the THFs, it was shown in Sec. 2 that after the initiation reactions, saturated, highly reactive aldehyde and ketone radicals are formed and that the length of the THF side chain directly relates to the length of the linear alkyl chain of the intermediate product, cf. Fig 3. It has been widely established that a long linear alkyl chain increases the low and intermediate temperature reactivity of a fuel [26] resulting in a higher ignitability under diesel relevant conditions. This results in larger DCN values for increasing chain lengths up to a certain carbon number. For larger molecules, no further increase of reactivity occurs.

The ignitability of the dihydrofurans in the IQT is higher than that of furan and lower than that of THF as expected considering the number of double bonds in the ring structures of furan, DHF, and THF. In addition, the dihydrofurans 2,3-DHF and 2,5-DHF illustrate the importance of the double bond location in the ring. The shift from the 4,5-position $(2,3-\mathrm{DHF})$ to the 3,4-position (2,5-DHF) induces a DCN decrease of 4.4, as the produced 2,5 -DHF-2R radical is more stable than the $2,3-\mathrm{DHF}-3 \mathrm{R}$ radical.

Finally, the addition of a hydroxyl group to the side chain of an alkylated furan and tetrahydrofuran further support the findings for furanic and tetrahydrofuranic species: The DCN of 2-FFOH was shown to be approximately the same as that of the corresponding 2-EF, whereas the DCN of 2THFFOH is smaller than that of any other tetrahydrofuranic species. Again, 
the influence of the ring structure prevails over that of the other functional groups. For the furanic 2-FFOH, the aromatic ring determines the ignition behavior and the influence of the side chains, paraffinic or with an alcohol functionality, is minor. Hence, the DCNs of 2-FFOH and 2-EF are very similar. The reduced reactivity of 2-THFFOH, on the other hand, can partly be due to the change of the reaction scheme. In addition, the physical properties (e.g. surface tension and vapor pressure) of the alcohols strongly differ from those of the alkylated fuels and may contribute to the increased ignition delay of 2-THFFOH.

\subsection{DCNs of fuel blends}

Current commercial bio-fuels such as ethanol and bio-diesel are mostly used in fuel blends with regular gasoline or diesel. Blending bio-fuels into standard fossil fuels eases the fuel compatibility with common vehicles and will most likely persist for the next-generation bio-fuels. Therefore, the ignition behavior of fuel blends consisting of furans and tetrahydrofurans with the base hydrocarbon reference fuel n-heptane was investigated in the IQT.

In Figure 7, the DCNs of the fuel blends are shown. It can be seen that the DCNs follow an approximately linear blending rule in terms of mol\%. The blending behavior in terms of mass $\%$ and vol $\%$ is additionally presented in the supplementary material.

For the detailed evaluation of fuel blends, the influence of the single components on the overall radical pool has to be discussed. In this study, nheptane is the most reactive fuel in all blends and hence feeds the radical pool. The added furans and THFs are either unreactive and merely dilute the mixture or they act as active radical sink, i.e. the fuel molecules react with radicals produced by $n$-heptane and form relatively more stable radicals and intermediates.

With respect to the IQT measurements, the unreactive, ring-dominated chemistry of the furanic species yields similar DCN results for all blends. Especially at blend fractions of less than $20 \mathrm{~mol} \%$ furans, the mixture DCNs are similar for all fuels from the furan group.

Nonetheless, the number of available H-atoms for initial abstraction (at the C6 carbon atom) impacts the furans' activity as radical sink. Hence, the deviation from the linear blending rule is strongest for 2,5-DMF with two available $\mathrm{H}$ atoms, whereas it is least for furan with no $\mathrm{C} 6$ carbon atom (cf. supplementary material, Fig. S2). The highly unreactive furan hence 
inhibits ignition the least for blend concentrations of up to $60 \mathrm{~mol} \%$. Its low reactivity is further the reason for the very low DCN of pure furan.

\section{Discussion}

BDEs for 2-EF, 2-BF, 2-FFOH, 2-ETHF, 2-BTHF, 2-THFFOH, 2,3-DHF and 2,5-DHF were calculated and used to establish an understanding of the auto-ignition process of these species. DCN measurements for a range of homologous pure-component furans, tetrahydrofurans, dihydrofurans, and furfuryl alcohols were presented, accompanied by blending studies for the ignition of furans and tetrahydrofurans in mixtures with the standard reference fuel n-heptane and a reference diesel.

It was found that the addition of side chains to the furan molecule has a minor impact on the ignitability of the fuel. Consequently, side chain effects can be neglected for engine applications of furans. This yields huge benefits concerning bio-fuel production pathways, which can be chosen exclusively according to efficiency, feasibility and economic considerations. Further, furan fuel structures can be selected with respect to their physical properties, e.g. vapor pressure and viscosity, for SI engine applications.

For the tetrahydrofurans, on the contrary, the side chain has a strong influence on the ignition behavior of the fuel and hence determines the desired combustion characteristics of the molecular structure. For engine applications, the side chain length of a THF is therefore crucial: THFs with a short side chain are candidates for gasoline replacement, whereas 2-BTHF is a potential diesel fuel.

Further, the addition of an alcohol group to the side chain was found to have different effects depending on the degree of saturation of the ring structure. For the saturated 2-THFFOH, the alcohol functionality strongly decreased the reactivity of the species, whereas the influence on the ignition behavior of the furanic species is marginal, as can be seen by the nearly identical DCNs of 2-EF and 2-FFOH. Finally, linear DCN mixture rules can be applied for furans and THF in blends with n-heptane.

\section{Acknowledgments}

This work was funded by the Cluster of Excellence "Tailor-Made Fuels from Biomass", which is funded by the Excellence Initiative by the German federal and state governments to promote science and research at German 
universities. AS would like to acknowledge the financial support of DAADDoktorandenstipendium. A three month Visiting Student Research Collaborator (VSRC) appointment (AS) and research at Princeton University was supported by the Energy Frontier Research Center entitled "From Fundamentals to Multi-scale Predictive Models for 21st Century Transportation Fuels", funded by the US Department of Energy, Office of Science, Office of Basic Energy Sciences under Award Number DE-SC0001198. We acknowledge Mr. Timothy Bennett at Princeton for assistance in maintaining experimental facilities.

[1] A. Janssen, M. Muether, S. Pischinger, A. Kolbeck, M. Lamping, T. Koerfer, SAE Technical Paper (2009) 2009-01-1811.

[2] A. Voll, W. Marquardt, Biofuel. Bioprod. Bior. 6 (3) (2012) 292-301.

[3] J. Julis, W. Leitner, Angew. Chem. Int. Ed. 51 (2012) 8615-8619.

[4] J.M. Simmie, H.J. Curran, J. Phys. Chem. A 113 (17) (2009) 5128-5137.

[5] Z. Tian, T. Yuan, R. Fournet, P.-A. Glaude, B. Sirjean, F. BattinLeclerc, K. Zhang, F. Qi, Combust. Flame 158 (4) (2011) 756-773.

[6] J.M. Simmie, J. Phys. Chem. A 116 (18) (2012) 4528-4538.

[7] K. Moshammer, S. Vranckx, H.K. Chakravarty, P. Parab, R.X. Fernandes, K. Kohse-Höinghaus, Combust. Flame 160 (2013) 2729-2743.

[8] B. Sirjean, R. Fournet, Phys. Chem. Chem. Phys. 15 (2013) 596-611.

[9] B. Sirjean, R. Fournet, P.-A. Glaude, F. Battin-Leclerc, W. Wang, M.A. Oehlschlaeger, J. Phys. Chem. A 117 (7) (2013) 1371-1392

[10] H.K. Chakravarty, R.X. Fernandes, J. Phys. Chem. A 117 (24) (2013) 5028-5041.

[11] W. Zhang, C. Feng, B. Du, L. Mu, Struct. Chem. 20 (2009) 525-532.

[12] G. Knothe, A.C. Matheaus, T.W. Ryan III, Fuel 82 (8) (2003) 971-975.

[13] L.A. Curtiss, K. Raghavachari, P.C. Redfern, V. Rassolov, J.A. Pople, J. Chem. Phys. 109 (18) (1998) 7764-7776. 
[14] Gaussian 09, M.J. Frisch, G.W. Trucks, H.B. Schlegel, G.E. Scuseria et al., Gaussian, Inc., Wallingford, CT, (2009).

[15] C. Cao, H. Yuan, J. Chem. Inf. Comput. Sci. 43 (2003) 600-608.

[16] T. Kasper, A. Lucassen, A.W. Jasper, W. Li, P.R. Westmoreland, K. Kohse-Höinghaus, B. Yang, J. Wang, T.A. Cool, N. Hansen, Z. Phys. Chem. 225 (2011) 1237-1270.

[17] K.A. Heufer, S.M. Sarathy, H.J. Curran, A.C. Davis, C.K. Westbrook, W.J. Pitz, Energy Fuels 26 (11) (2012) 6678-6685.

[18] K.P. Somers, J.M. Simmie, F. Gillespie, C. Conroy, G. Black, W.K. Metcalfe, F. Battin-Leclerc, P. Dirrenberger, O. Herbinet, P.-A. Glaude, P. Dagaut, P., C. Togbé, K. Yasunaga, R.X. Fernandes, C. Lee, R. Tripathi, H.J. Curran, Combust. Flame 160 (11) (2013) 2291-2318.

[19] F.M. Haas, A. Ramcharan, F.L. Dryer, Energy Fuels 25 (9) (2011) 39093916.

[20] P. Ghosh, Energy Fuels 22 (2) (2008) 1073-1079.

[21] ASTM D6890.

[22] ASTM D613.

[23] F.M. Haas, F.L. Dryer, Fall Technical Meeting, Eastern States Section of the Combution Institute (2013) Clemson, SC.

[24] M. Ribaucour, R. Minetti, L.R. Sochet, Proc. Combust. Inst. 27 (1) (1998) 345-351.

[25] G. Vanhove, G. Petit, R. Minetti, Combust. Flame 145 (3) (2006) 521532.

[26] C.K. Westbrook, W.J. Pitz, O. Herbinet, H.J. Curran, E.J. Silke, Combust. Flame 156 (1) (2009) 181-199. 


\section{List of figure captions}

- Figure 1: Evaluated fuel structures.

- Figure 2: Initial reactions of alkylated furans; $\mathrm{R}_{1}: \mathrm{H}, \mathrm{CH}_{3} ; \mathrm{R}_{2}: \mathrm{CH}_{3}$, $\mathrm{C}_{2} \mathrm{H}_{5}, \mathrm{C}_{4} \mathrm{H}_{9}$.

- Figure 3: Ring opening of tetrahydrofurans.

- Figure 4: Furans in mixture with n-heptane and diesel.

- Figure 5: Derived cetane numbers.

- Figure 6: Side chain and double bond influence.

- Figure 7: DCNs of fuel/n-heptane mixtures. 


\section{Tables}

Table 1: Bond dissociation energies.

\begin{tabular}{|c|c|c|c|}
\hline Furans & {$\left[\mathrm{kJ} \mathrm{mol}^{-1}\right]$} & THFs & {$\left[\mathrm{kJ} \mathrm{mol}^{-1}\right]$} \\
\hline \multicolumn{4}{|c|}{ H-abstraction from side chain carbon } \\
\hline $2-\mathrm{MF}-\mathrm{C} 6 \mathrm{R}^{a, d}$ & $360.9 \pm 5.2$ & 2-MTHF-C6R ${ }^{c}$ & 431.3 \\
\hline $3-\mathrm{MF}-\mathrm{C} 6 \mathrm{R}^{a}$ & $377.9 \pm 5.3$ & & \\
\hline $2-\mathrm{EF}-\mathrm{C} 6 \mathrm{R}^{c}$ & 351.0 & 2-ETHF-C6R ${ }^{c}$ & 421.0 \\
\hline $2-\mathrm{EF}-\mathrm{C} 7 \mathrm{R}^{c}$ & 430.2 & 2-ETHF-C7R ${ }^{c}$ & 429.9 \\
\hline $2-\mathrm{BF}-\mathrm{C} 6 \mathrm{R}^{c}$ & 352.9 & 2-BTHF-C6R ${ }^{c}$ & 425.2 \\
\hline $2-\mathrm{BF}-\mathrm{C} 7 \mathrm{R}^{c}$ & 418.9 & 2-BTHF-C7R ${ }^{c}$ & 418.8 \\
\hline $2-\mathrm{BF}-\mathrm{C} 8 \mathrm{R}^{c}$ & 415.0 & $2-\mathrm{BTHF}-\mathrm{C} 8 \mathrm{R}^{c}$ & 417.1 \\
\hline $2-\mathrm{BF}-\mathrm{C} 9 \mathrm{R}^{c}$ & 427.2 & 2-BTHF-C9R ${ }^{c}$ & 426.6 \\
\hline $2,5-\mathrm{DMF}-\mathrm{C} 6 \mathrm{R}^{a}$ & $357.8 \pm 5.9$ & 2,5 -DMTHF-C6R ${ }^{b}$ & $431.8 \pm 1.2$ \\
\hline FFOH-C6R ${ }^{c}$ & 343.7 & THFFOH-C6R ${ }^{c}$ & 403.7 \\
\hline FFOH-O7R ${ }^{c}$ & 442.8 & THFFOH-O7R $^{c}$ & 440.5 \\
\hline \multicolumn{4}{|c|}{ H-abstraction from ring carbon } \\
\hline \multirow{3}{*}{$\begin{array}{l}\mathrm{F}-2 \mathrm{R}^{a} \\
\mathrm{~F}-3 \mathrm{R}^{a}\end{array}$} & $504.6 \pm 5.6$ & THF- $2 \mathrm{R}^{b}$ & $392.4 \pm 0.7$ \\
\hline & $505.0 \pm 5.5$ & $\mathrm{THF}-3 \mathrm{R}^{b}$ & $411.6 \pm 0.2$ \\
\hline & & $2-\mathrm{MTHF}-2 \mathrm{R}^{c}$ & 388.5 \\
\hline $2-\mathrm{MF}-3 \mathrm{R}^{a}$ & $504.5 \pm 5.7$ & 2-MTHF-3R ${ }^{c}$ & 415.5 \\
\hline $2-\mathrm{MF}-4 \mathrm{R}^{a}$ & $503.7 \pm 5.7$ & $2-\mathrm{MTHF}-4 \mathrm{R}^{c}$ & 410.5 \\
\hline $2-\mathrm{MF}-5 \mathrm{R}^{a}$ & $503.7 \pm 5.7$ & 2 -MTHF-5R ${ }^{c}$ & 392.0 \\
\hline $3-\mathrm{MF}-2 \mathrm{R}^{a}$ & $504.8 \pm 5.8$ & & \\
\hline $3-\mathrm{MF}-4 \mathrm{R}^{a}$ & $503.9 \pm 5.7$ & & \\
\hline \multirow{2}{*}{$3-\mathrm{MF}-5 \mathrm{R}^{a}$} & $502.4 \pm 5.8$ & & \\
\hline & & 2 -ETHF-2R ${ }^{c}$ & 392.5 \\
\hline $2-\mathrm{EF}-3 \mathrm{R}^{c}$ & 503.5 & 2-ETHF-3R ${ }^{c}$ & 414.5 \\
\hline $2-\mathrm{EF}-4 \mathrm{R}^{c}$ & 502.8 & 2 -ETHF-4R ${ }^{c}$ & 413.3 \\
\hline \multirow[t]{2}{*}{$2-E F-5 R^{c}$} & 502.1 & 2-ETHF-5R ${ }^{c}$ & 395.1 \\
\hline & & 2 -BTHF-2R $\mathrm{R}^{c}$ & 392.3 \\
\hline $2-\mathrm{BF}-3 \mathrm{R}^{c}$ & 503.3 & $2-\mathrm{BTHF}-3 \mathrm{R}^{c}$ & 414.4 \\
\hline $2-\mathrm{BF}-4 \mathrm{R}^{c}$ & 502.7 & 2 -BTHF- $4 \mathrm{R}^{c}$ & 413.2 \\
\hline \multirow[t]{2}{*}{$2-\mathrm{BF}-5 \mathrm{R}^{c}$} & 502.0 & $2-\mathrm{BTHF}-5 \mathrm{R}^{c}$ & 394.4 \\
\hline & & 2,5 -DMTHF- $2 \mathrm{R}^{b}$ & $387.7 \pm 0.8$ \\
\hline \multirow{2}{*}{$2,5-\mathrm{DMF}-3 \mathrm{R}^{a}$} & $503.3 \pm 5.6$ & 2,5 -DMTHF-3R ${ }^{b}$ & $414.5 \pm 0.1$ \\
\hline & & THFFOH-2R $\mathrm{R}^{c}$ & 397.2 \\
\hline FFOH-3R ${ }^{c}$ & 508.3 & THFFOH-3R ${ }^{c}$ & 414.8 \\
\hline FFOH- $4 \mathrm{R}^{c}$ & 502.5 & THFFOH- $4 \mathrm{R}^{c}$ & 414.6 \\
\hline FFOH-5R ${ }^{c}$ & 503.2 & THFFOH-5R ${ }^{c}$ & 396.2 \\
\hline \multicolumn{4}{|c|}{ Methyl group abstraction } \\
\hline $2-\mathrm{MF}-2 \mathrm{R}^{a}$ & $479.4 \pm 5.6$ & 2 -MTHF-2R ${ }^{b}$ & $361.6 \pm 2.4$ \\
\hline $3-\mathrm{MF}-3 \mathrm{R}^{a}$ & $479.8 \pm 5.8$ & & \\
\hline $2,5-\mathrm{DMF}-5 \mathrm{R}^{a}$ & $479.8 \pm 5.8$ & 2,5 -DMTHF-2R ${ }^{b}$ & $360.8 \pm 2.1$ \\
\hline DHFs & {$\left[\mathrm{kJ} \mathrm{mol}^{-1}\right]$} & DHFs & {$\left[\mathrm{kJ} \mathrm{mol}^{-1}\right.$} \\
\hline $2,3-\mathrm{DHF}-2 \mathrm{R}^{c}$ & 394.0 & $2,5-\mathrm{DHF}-2 \mathrm{R}^{c}$ & 329.9 \\
\hline $2,3-\mathrm{DHF}-3 \mathrm{R}^{c}$ & 343.8 & $2,5-\mathrm{DHF}-3 \mathrm{R}^{c}$ & 485.4 \\
\hline $2,3-\mathrm{DHF}-4 \mathrm{R}^{c}$ & 496.5 & & \\
\hline $2,3-\mathrm{DHF}-5 \mathrm{R}^{c}$ & 487.6 & & \\
\hline
\end{tabular}


Furans

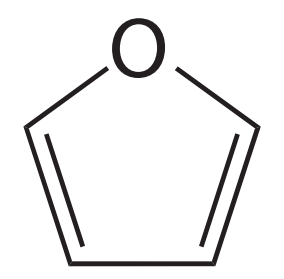

Furan



2-MF



2-EF
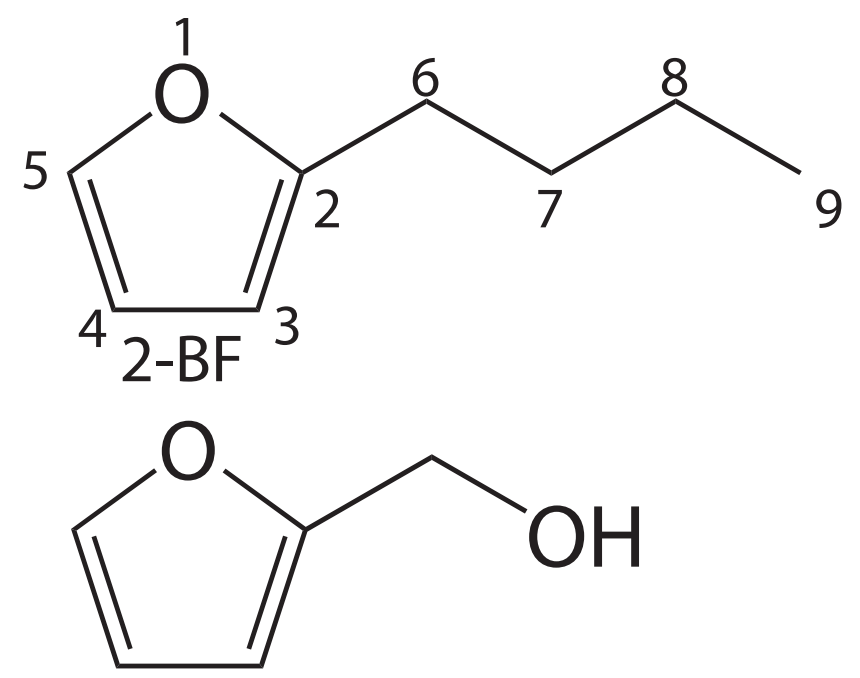

2-FFOH
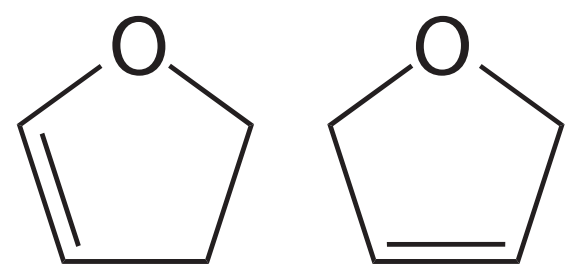

2,3-DHF 2,5-DHF

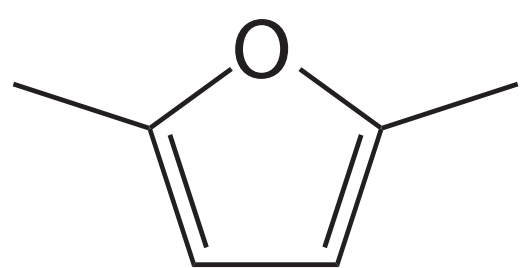

2,5-DMF
THFs


2-MTHF

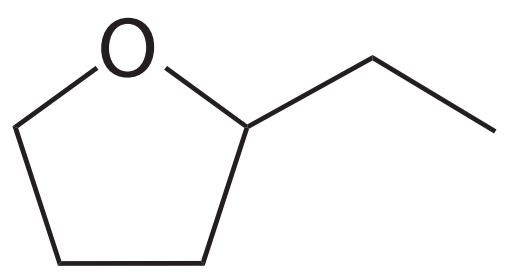

2-ETHF

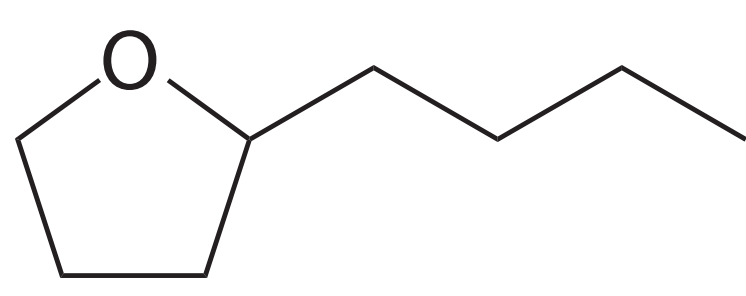

2-BTHF

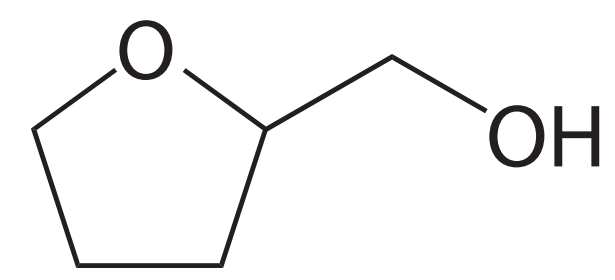

2-THFFOH 
Figure 4: Furans in mixture with n-heptane and diesel.

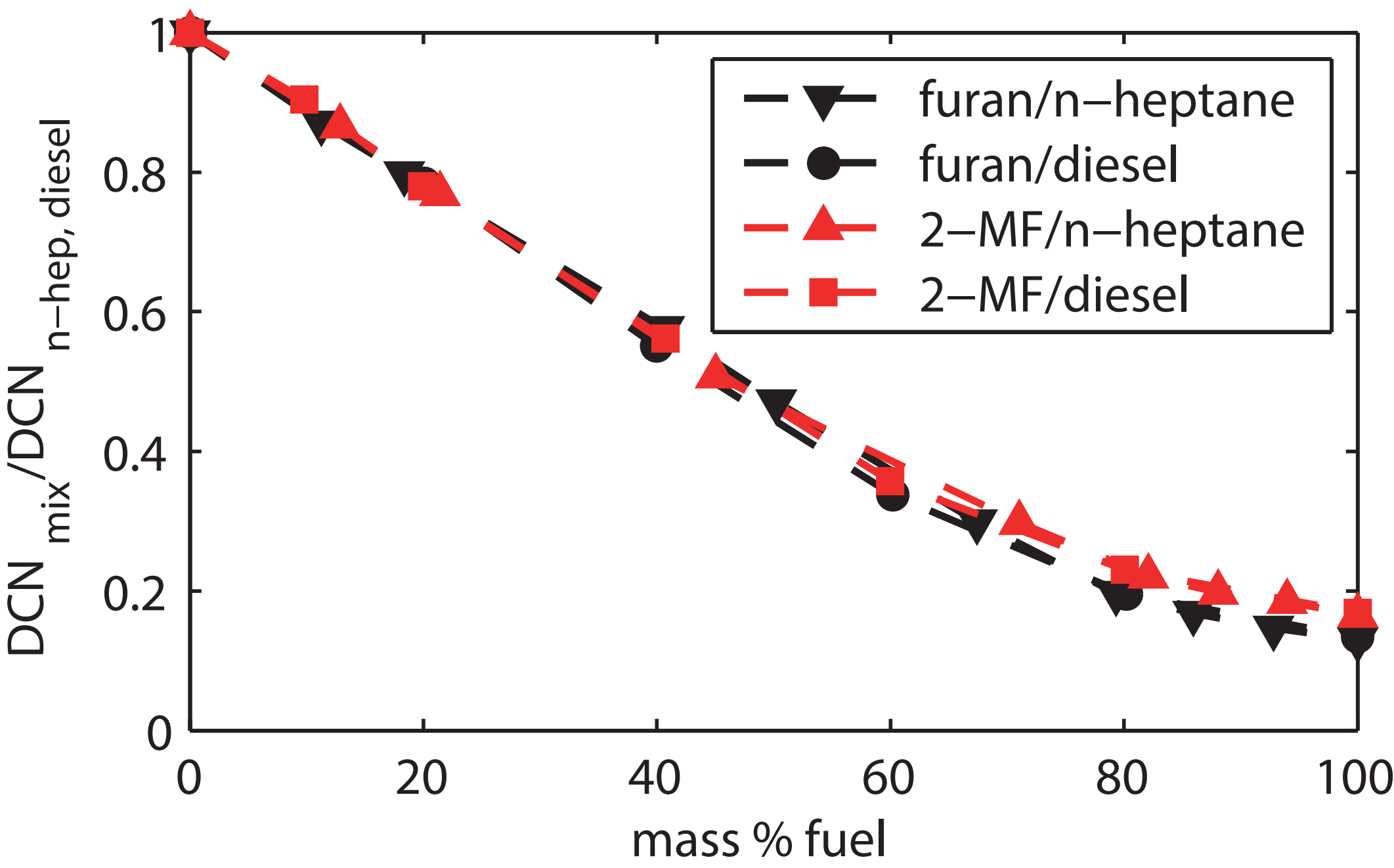


Figure 5: Derived cetane numbers.

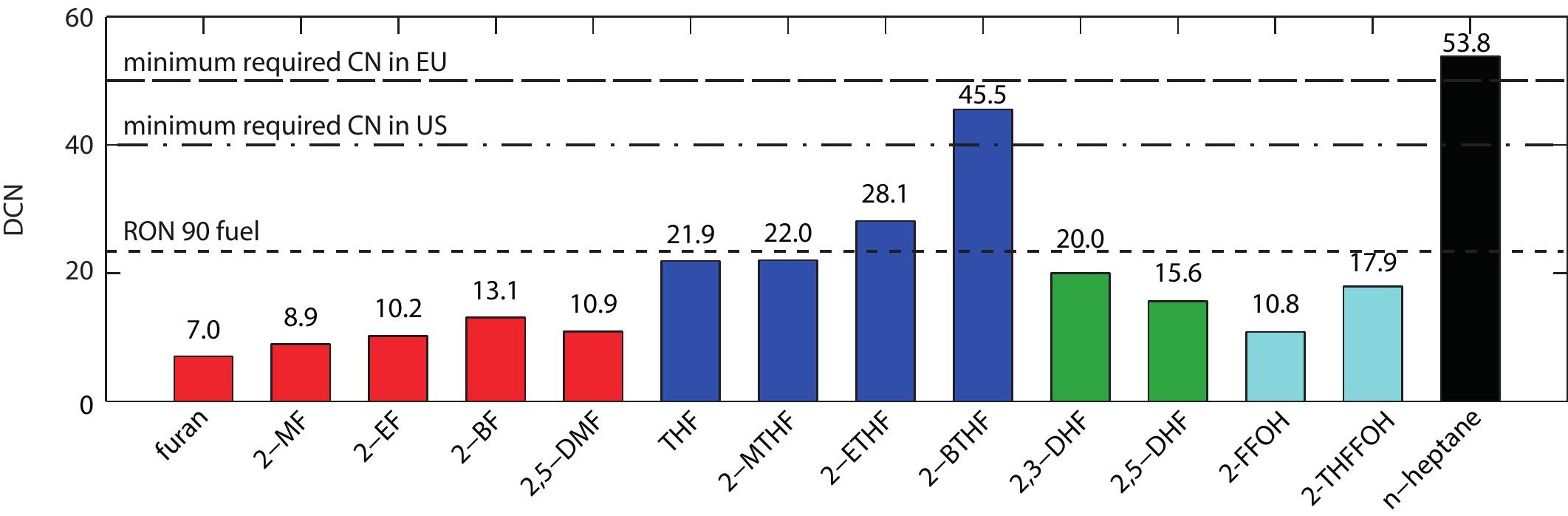


Figure 6: Side chain and double bond influence.



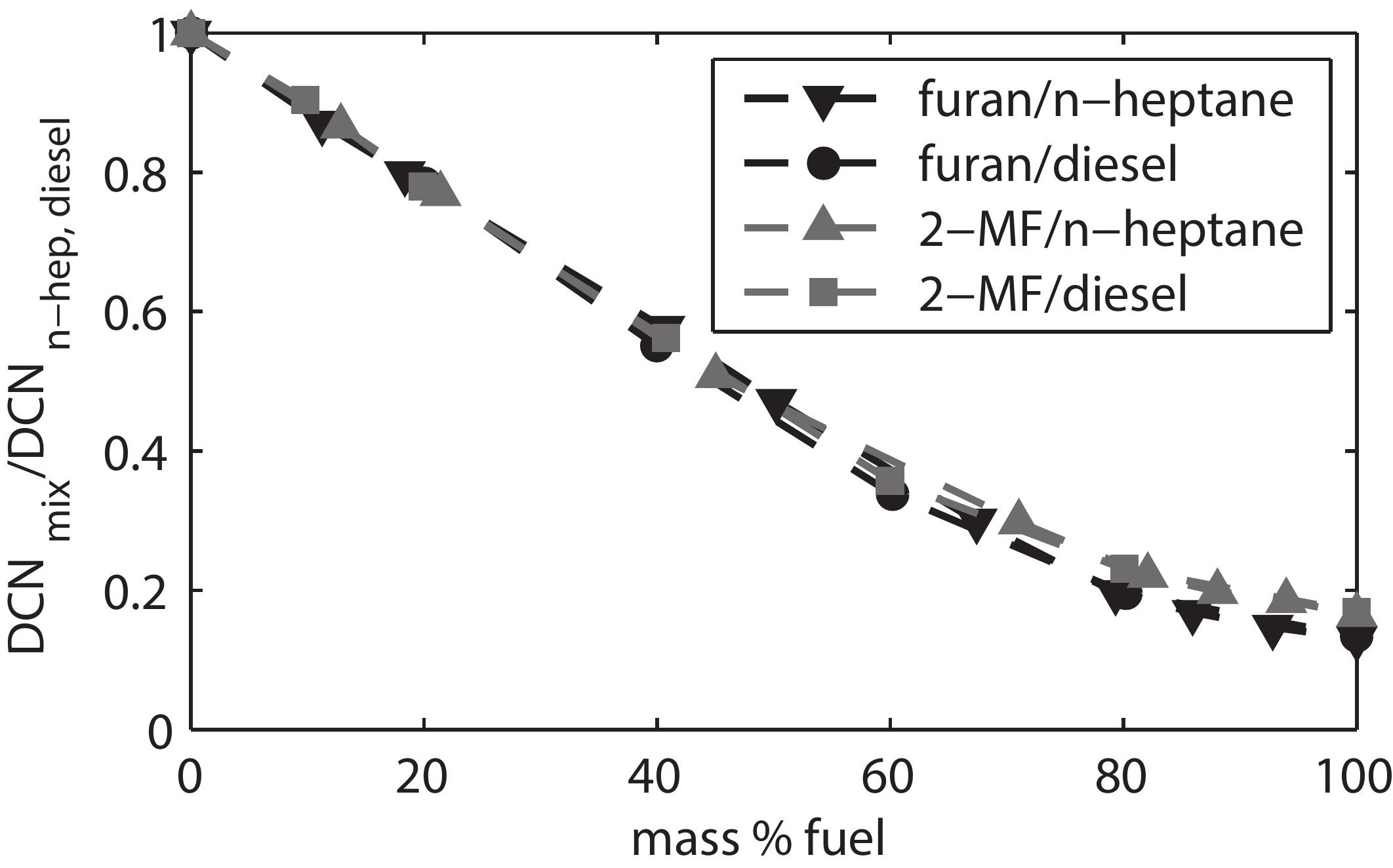

Figure 4 , grayscale version 


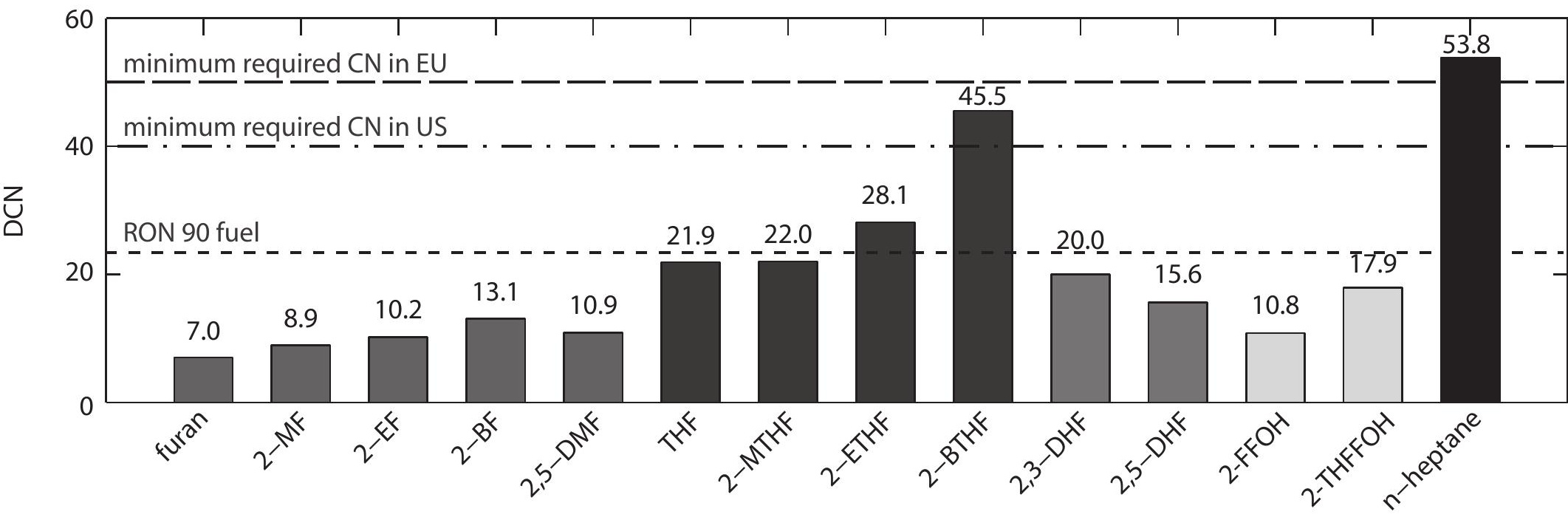


Figure 6 , grayscale version
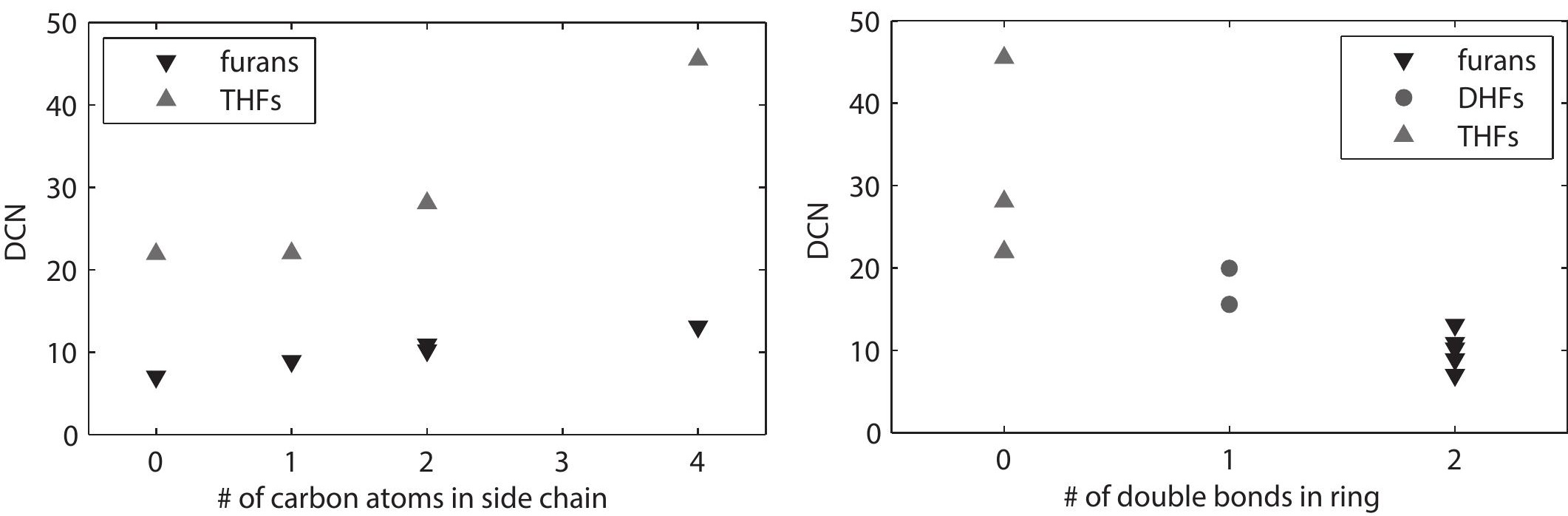


mol \% fuel

$$
\text { mol \% fuel }
$$

